\title{
Characteristics of nursing home units with high versus low levels of person-centred care in relation to leadership, staff- resident- and facility factors: findings from SWENIS, a cross-sectional study in Sweden
}

\author{
Annica Backman ${ }^{1 *}$ (D) Per-Olof Sandman ${ }^{1,2}$ and Anders Sköldunger ${ }^{1,3}$
}

\begin{abstract}
Background: The context of care consists of factors that determines the extent to which staff can offer personcentred care. However, few studies have investigated factors that can explain variation in levels of person-centred care among nursing home units. The aim of this study was to explore factors characterizing nursing home units with high and low degree of person-centred care, with focus on leadership, staff, resident and facility factors.

Methods: Cross-sectional data from residents, staff, and managers in 172 randomly selected nursing homes in Sweden were collected in 2014. Activities of Daily Living Index, Gottfries' cognitive scale, Person-centred Care Assessment Tool together with demographic information and estimations of leadership engagement was used. Independent samples t-test and Chi2 test were conducted.

Results: Highly person-centred units were characterised by leaders engaging in staff knowledge, professional development, team support and care quality. In highly person-centred units' staff also received supervision of a nurse to a larger extent. Highly person-centred units were also characterised as dementia specific units, units with fewer beds and with a larger proportion of enrolled nurses. No differences in degree of person-centred care were seen between public or private providers.

Conclusions: This study provides guidance for practitioners when designing, developing and adapting personcentred units in aged care contexts. Managers and leaders have an important role to promote the movement towards a person-centred practice of care, by supporting their staff in daily care, and engaging in staff knowledge and professional development. Targeting and adjusting environmental factors, such as provide small and dementia adapted environments to match the residents' personal preferences and capacity are also important when striving towards person-centredness.
\end{abstract}

Keywords: Person centred care, Physical environment, Leadership, Nursing management, Nursing homes, Organisation of care

\footnotetext{
* Correspondence: annica.backman@umu.se

${ }^{1}$ Department of Nursing, Umeå University, SE-901 87 Umeå, Sweden

Full list of author information is available at the end of the article
}

(c) The Author(s). 2021 Open Access This article is licensed under a Creative Commons Attribution 4.0 International License, which permits use, sharing, adaptation, distribution and reproduction in any medium or format, as long as you give appropriate credit to the original author(s) and the source, provide a link to the Creative Commons licence, and indicate if changes were made. The images or other third party material in this article are included in the article's Creative Commons licence, unless indicated otherwise in a credit line to the material. If material is not included in the article's Creative Commons licence and your intended use is not permitted by statutory regulation or exceeds the permitted use, you will need to obtain permission directly from the copyright holder. To view a copy of this licence, visit http://creativecommons.org/licenses/by/4.0/. The Creative Commons Public Domain Dedication waiver (http://creativecommons.org/publicdomain/zero/1.0/) applies to the data made available in this article, unless otherwise stated in a credit line to the data. 


\section{Background}

Moving away from task-oriented models of care, towards a more person-centred practice is now guiding the provision of care in nursing homes worldwide. The care context has been described as a decisive factor for the extent to which staff can provide person-centred care, but only a few studies have empirically investigated which factors define nursing home units as being more or less person-centred. To gain insight in determinants enhancing person-centred care with respect to personal factors (leadership, staffing and resident) as well as structural (facility) is essential.

The concept person-centred care is commonly used to indicate a holistic view of the person in need of care, respecting subjective experiences, values, needs and preferences [1-3]. Studies has shown that residents may benefit from this approach. Among persons living with dementia, it has been shown that person-centred care has been associated to higher quality of life $[4,5]$. A person-centred intervention including staff education, environmental adaptation and a variety of daily activities for residents was shown to improve well-being among residents [6]. Also, Dementia Care Mapping (DCM) increased well-being among residents and reduced depressive symptoms in a person-centred intervention by Rokstad et al. [7]. A cluster-randomized trial showed that DCM and staff training in dementia care were associated with reduced agitation among nursing home residents [8]. However, opposite findings are also evident in previous literature as person-centred intervention studies with no or negative effect also has been reported. An individualised tailored intervention did not significantly change quality of life among residents [9] and an activity-oriented intervention showed no reduction in anxiety [10]. An increased number of falls accidents among residents were also reported from a personcentred intervention, while DCM reduced resident falls [8]. Positive impact on staff health and work situation has also been reported in previous literature. Working in a person-centred manner has been associated with higher degree of job satisfaction [11-14], higher psychosocial climate [13] lower degree of stress of conscience and lower degree of job strain $[13,15]$. Taken together, available evidence indicates that person-centred care has predominantly beneficial outcomes wereas why person-centred practices have been declared by WHO as a global strategy to address the variety of care needs due to an aging population $[1,16]$ Although person-centred care is increasingly embraced and recommended by aged care providers, practitioners and the research society as the "gold standard" model of care [1, 10, 17, 18], there still remain challenges in putting a personcentred philosophy into practice [11].
Quality of leadership has been described as having potential to support or hinder person-centred practices [2, 19]. Until recently, a large amount of PCC intervention publications have, besides focusing on implementing PCC, and also highlighted the significance of leadership [20-23]. An intervention study using DCM have reported that managers who take an active part in the care practice, have clear visions, are supportive and act as role models with a leadership based on a person-centred philosophy, beneficially influenced the implementation of PCC in nursing homes [20]. Other studies have also reported that managers who promotes interpersonal relationships, communicating with staff with sensitivity, inclusion and respect affect implementation of a PersonCentred Care program [21] and a DCM intervention in a positive way [22]. One study showed that leadership is positively associated to degree of PCC in Swedish nursing homes [24]. Furthermore, staff in nursing home units in Sweden offering a high degree of PCC seem to be more satisfied with the leadership than units with low degree of PCC [25]. However, managerial obstacles have also been reported in previous studies where manager and leader resistance to change have been indicated as a barrier to enable person-centred practice [26]. A cluster randomized controlled trial of person-centred residential care by Chenoweth et al. [23] reported that the implementation effectiveness was low when the manager focused more on organisational efficiency than on enabling resident comfort and pleasure. In contrast, Jeon et al. [27] was not able to see any changes in terms of person-centred care after a 12-month leadership development programme, in their controlled trial. A systematic literature review concluded that leadership is a vital part of the implementation process in nursing, but research has still not specified in what way, and therefore suggests that more research is needed to explore the possible role of the leader [28]. Thus, although the quality of leadership has been described to have high potential to support or hinder person-centred practices [2, 19], there seems to be a limited consensus on leadership determinants enabling successful delivery of PCC.

The theoretical discourse has postulated that the organisational and contextual factors are critical for person-centred processes $[2,19]$. A factor that has been pointed out as an important prerequisite for PCC, is staff competence [2]. A Canadian study showed that demographic characteristics of the staff (e.g., age, education, experience, job classification, ethnicity, work status) did not influence the provision of PCC, neither did facility characteristics (e.g., facility size, presence of a union, managers experience) [29]. In contrast, a Swedish study showed that units with high PCC had a more adapted environment and higher degree of staff educated for care of persons with dementia. Furthermore, staff in units 
with higher degree of PCC to a larger extent received regular supervision as well as reported satisfaction with leadership compared to units with lower degree of PCC [25]. In terms of other contextual factors such as ownership of the facility, it has been shown that public nursing homes has been related to higher quality in terms of higher staffing levels and offering individual accommodation/kitchen, but scored lower in terms of processual quality such as user participation, updated care plans and medication reviews, when comparing with private nursing homes [30].

Although the way leadership is performed can play an important role in PCC processes, there seems to be a lack of scientific consensus underpinning this assumption. Although the context of care delivery is increasingly recognised, organisational and contextual actors facilitating person-centred care are mainly based on theoretical models, with limited empirical knowledge on which factors actually characterise nursing home units offering different degree of PCC. Thus, it's essential to gain insight in determinants enhancing person-centred care with respect to personal factors (leadership, staffing and resident) as well as structural (facility) therefor seems essential. The aim of this study was to explore factors characterizing high and low person-centred nursing home units, with focus on leadership, staff, resident and facility variables.

\section{Methods \\ Design}

The present study is part of the Swedish National Inventory of Care and Health in Residential Aged Care (SWENIS), a nationwide randomized longitudinal project with explorative design within The Umeå ageing and health research programme (U-AGE) [31]. The UAGE research programme provides translational knowledge on the structure, content and outcomes of personcentred care and health-promoting living conditions in nursing homes for older people and people with dementia. The cross-sectional data for this study was collected between November 2013 and September 2014.

\section{Sampling}

Out of 290 Swedish municipalities, a random selection of 60 municipalities was invited to participate in the project. Of the 60 municipalities 35 agreed to participate, contributing with data from 172 nursing homes. The final sample included data from staff $n=3605$ (response rate $66.5 \%$ ), residents $n=4831$ (response rate $70 \%$ ) and managers $(n=191)$. As this study is part of a large research programme [31], a more detailed description of sampling and data collection can found be in previous publications [24, 31].

\section{Data collection}

Data was collected using a three-part survey that were sent out to the invited nursing homes. A self-reported staff survey comprising demographic information together with estimations of leadership engagement and person-centred care. All direct care staff working day/ evening shifts with long-term employments were invited to participate. A resident survey collected demographic information about the residents together with assessments of the residents ADL and cognitive status. This survey was completed by the staff member who knew the resident best, their primary carer, through proxyrating. Each primary carer commonly assessed one residents each. The third survey was an organisational survey consisting of questions about leadership and organisational characteristics about the nursing home. This part was completed by the managers.

\section{Characteristics of workforce and study context}

In Sweden, nursing home managers have the operational responsibility for the care of residents, direct care staff and the work environment [32] and a qualification of social work or nursing care seems to be most common although no formal education is required to hold a managerial position in Sweden [33]. Registered nurses are responsible for the nursing care provision and medical care [34]. The direct care staff consists primarily of enrolled nurses and nurse assistants [34] and they are responsible for providing personal care and social services to residents [35]. Direct care staff consists primarily of enrolled nurses who have upper secondary level schooling (up to 3 years of training), with a level 4 qualification in the European Qualifications Framework [36] and nurses' assistant who have approximately, half the length of training/education ( $<1$ year) with one level lower qualification in EQF [37-40]. The European Qualifications Framework is a translation device explicating qualification requirements within different educations and training systems in Europe [36]. Regular tasks for nurse assistants includes care assistance, making beds, helping patients with nutrition and hygiene, while enrolled nurses in addition also tests glucose, temperature, pulse, respiration and weight, carrying out simple changing bandages, conducting simple laboratory tests and giving medication on delegation from reg. nurse [39]. Swedish nursing homes are defined as housing for people 65 years and older, who are no longer able to live at home [41]. About 82,000 residents resides in nursing homes due to extensive personal care needs and/or cognitive impairment $[37,42]$. The number of beds in municipal aged care in Sweden has decreased from 120,000 since 2000 although the proportion of older persons is growing and in 2014 the beds were 108,835 [43]. Swedish aged care is mainly funded publicly and essentially 
publicly produced, and the specification of the national policies postulates that older persons should have the possibility to live independently with high quality of life and furthermore that high-quality care should be provided to older persons in need of care [44].

\section{Study variables}

Demographic data including staff characteristics (sex, age, qualifications, work experience) and resident characteristics (sex, age) as well as organisational characteristics of the facility (number of beds, SCU/general unit, private/public provider).

\section{Leader engagement and support}

The extent to which staff perceived leader engagement and support were investigated by six study-specific single items inspired by Hällsten \& Tengbland [45], and Beck [46],; To what extent is your manager engaged in issues related to your knowledge/skills at work? To what extent is your managers engaged in issues related to your professional development at work? To what extent is your manager aware of the quality of the work you do? To what extent does your manager support you in providing care that is based on the individual older person's needs? To what extent does your manager consciously work to improve the team spirit/mood of the staff group? To what extent do you get supervision of a reg. nurse in the direct care provision? The items are rated on a five-point Likert scale, ranging from 1 (to a very small extent) to 5 (to a very large extent). Higher scores implied that staff to a larger extent agreed with the statement. The studyspecific items were treated as single items in the analyses.

\section{Activities of daily living}

Functional function of the residents was measured using a modified version of the Katz Activities of Daily Living Index (ADL) [47] previous published in K. Hulter Åsberg (1990) [48] which measures daily activities in six domains: eating, transferring, dressing, bathing, toileting, and continence. Each domain was scored dichotomously as dependent (0) or fully independent (1) to obtain a total score of 0-6 points. Higher score indicates a more independent functional function. Functional independence was defined as dependent or independent where dependence included person's dependent in at least three of six items on the Katz ADL index [49].

\section{Gottfries' cognitive scale (GCS)}

Cognitive function was assessed using the scale developed by Gottfries and Gottfries [50], previously published in M. Gustafsson, U. Isaksson, S. Karlsson, PO. Sandman, H. Lovheim (2016). GCS consists of 27 items regarding ability to orientate. Statements are answered with a 'yes' ( 1 point) or 'no' ( 0 point). The range of the scale is $0-27$ and high scores indicate a better orientation ability. Scores $<24$ indicate cognitive impairment. Cut-off and criterion validity have been established against the Mini-Mental State Examination and been confirmed by Lövheim [51].

\section{Person-centred care assessment tool}

The Swedish version of the Person-centred Care Assessment Tool (P-CAT) used to assess the extent to which the staff perceived care as being person-centred [52, 53]. P-CAT was developed by D. Edvardsson, D. Fetherstonhaugh, R. Nay and S. Gibson [52] and later translated to Swedish by K. Sjogren, M. Lindkvist, PO. Sandman, K. Zingmark and D. Edvardsson [53]. The Person-centred Care Assessment Tool includes 13 items rated on a fivepoint Likert scale, ranging from 1 (disagree completely) to 5 (agree completely). The total score is calculated with a possible range between 13 and 65 and higher scores indicate higher levels of person-centred care. As five items were negatively worded in P-CAT, (Items 7, 8, 9,10 , and 12) these were reversed before statistical analysis. Permission to use P-CAT was obtained from Professor D. Edvardsson. Free of charge.

\section{Data analyses}

Data was analysed using SPSS statistics version 25. Normality was tested using Kolmogorov-Smirnov and visual examination of the histogram. Up to two missing items in the P-CAT instrument were replaced with the mean value of the individual for the total scale $(<8 \%$ of scale missing) [54]. A sample size calculation has been conducted for the SWENIS project and reported in previous literature $[55,56]$, indicating that a sample of 4500 residents would provide enough power to answer the U-Age SWENIS research questions at the 0.05 significance level. As a first step, staff-, resident- and facility characteristics were explored using descriptive statistics. Secondly, P-CAT was aggregated on unit level (mean value for the unit), and divided into two groups; units with higher mean values of P-CAT than the mean for all included nursing homes (49.78 points) and a second cohort including care units with a P-CAT score below the mean. As P-CAT was normally distributed a mean split was deemed appropriate. Thirdly, differences in leader engagement and support as well as staff-, resident- and facility characteristics between units with higher and lower levels of PCC were explored using independent samples t-test and Chi2 test.

\section{Results}

Direct care staff consisted of mostly women (95.3\%) with a mean age of 46.6 years (SD 11.3) and enrolled nursing was the most common qualification (82.5\%). Direct care 
staff had 9.9 years (SD 8.0) as the average work experience in the nursing home. Nursing home managers $(n=191)$ were mostly women $(91.0 \%)$ with a mean age of 49.6 years (SD 9.0) and they had been working as managers for approximately 3.4 years (SD 3.4) in that specific nursing home. Among managers, a social work degree was the most common educational qualification (47.9\%) followed by registered nurse qualification (27.7\%) and enrolled nursing (9.0\%) qualifications. Approximately, $4.3 \%$ of the managers were human resource specialists and $11.2 \%$ had other qualifications. The sample of residents was comprised of mostly women (67.8\%) and the mean age was 85.5 years. Their mean stay in the unit was about 30 months, and the majority were ADL dependent (84\%) and cognitively impaired (66.6\%) (see Tables 1 and 2). The participating nursing homes consisted of both regular units for older people (69.1\%) and special care units for dementia (SCU) (30.9\%). The number of beds varied between the nursing homes, 7-128 (mean 38) and most nursing homes were public $(93.5 \%)$.

\section{Comparison of leader engagement and support in units with high and low scorers of PCC}

When comparing how leader engagement and support were experienced by staff in units with higher and lower scoring of PCC, all variables were significantly higher in units scoring higher in PCC (see Table 3).

Table 1 Characteristics of staff $(n=3605)$ and managers $(n=191)$

\begin{tabular}{|c|c|c|}
\hline Staff & $\mathrm{n}^{1}(\%)$ & m (SD) \\
\hline Age (Years) & & $46.6(11.3)$ \\
\hline \multicolumn{3}{|l|}{ Sex } \\
\hline Men & $167(4.7)$ & \\
\hline Women & $3401(95.3)$ & \\
\hline \multicolumn{3}{|l|}{ Qualifications } \\
\hline Registered nurses & $12(0.3)$ & \\
\hline Enrolled nurses & $2918(82,6)$ & \\
\hline Nurse's assistants & $463(13.1)$ & \\
\hline No formal qualifications & $82(2.3)$ & \\
\hline Other education & $60(1.7)$ & \\
\hline Years of experience in aged care (mean $\pm S D)$ & & $17.9(10.3)$ \\
\hline Years in this nursing homes (mean $( \pm S D)$ & & $9.9(8.0)$ \\
\hline \multicolumn{3}{|l|}{ Work shift } \\
\hline Day shift & $80(2.2)$ & \\
\hline Day and evening & $3140(88.2)$ & \\
\hline Day, evening, night shift & $318(8.9)$ & \\
\hline Managers & $n^{2}(\%)$ & m (SD) \\
\hline Age (Years; mean \pm SD) & & $49.6(9.0)$ \\
\hline \multicolumn{3}{|l|}{ Sex } \\
\hline Men & $17(9.0)$ & \\
\hline Women & $172(91.0)$ & \\
\hline \multicolumn{3}{|l|}{ Qualifications } \\
\hline Registered nurses & $52(27.7)$ & \\
\hline Enrolled nurses & $17(9.0)$ & \\
\hline Social work & $90(47.9)$ & \\
\hline Human resource specialist & $8(4.3)$ & \\
\hline Other education & $21(11.2)$ & \\
\hline
\end{tabular}

Years of experience in aged care (mean \pm SD)

${ }^{1} \mathrm{n}$ does not always add up to 3605 in all variables due to missing items varariables due to missing items

${ }^{2} \mathrm{n}$ does not always add up to 191 in all variables due to missing items 
Table 2 Characteristics of residents $(n=4831)$

\begin{tabular}{|c|c|c|}
\hline & $n^{1}(\%)$ & m (SD) \\
\hline Age (Years) & & $85.5(7.8)$ \\
\hline \multicolumn{3}{|l|}{ Sex } \\
\hline Men & $1538(32.2)$ & \\
\hline Women & $3239(67.8)$ & \\
\hline \multicolumn{3}{|l|}{ ADL Capacity } \\
\hline Independent & $716(16)$ & \\
\hline Dependent & $3768(84)$ & \\
\hline \multicolumn{3}{|l|}{ Cognitive impairment } \\
\hline Yes & $2827(66.6)$ & \\
\hline No & $1418(33.4)$ & \\
\hline Residing in SCU & $1778(37.8)$ & \\
\hline Residing in general units & $2931(62.2)$ & \\
\hline Length of stay in months (mean \pm SD & & $30.5(33.1)$ \\
\hline
\end{tabular}

Comparison of staff, resident and facility characteristics in units with high and low scores of PCC

There were no significant differences between staff in units with higher and lower scores of PCC in relation to age, sex and years of experience in aged care (see Table 4). In units with higher scores of PCC, a significantly higher proportion of staff $(84.6 \%)$ were enrolled nurses compared to units with lower scores of PCC $(80.7 \%)(p=<0.002)$. Units with higher scores of PCC had a significantly lower proportion of nurse's assistants (11.8\%) compared to units with lower scores of PCC $(14.2 \%)(p=0.021)$. Units with higher scores of PCC had a significantly lower proportion of other education (1.7\%) compared to units with lower scores of PCC $(2.2 \%)(p=0.016)$. In units with higher scores of PCC, staff work experience in current nursing home unit were significantly shorter (9.6 year), compared to units with lower scores of PCC (10.2 year) $(p=0.029)$ (see Table 4$)$.

There were no significant differences in terms of resident age, sex and length of stay between units with higher and lower scores of PCC. When comparing facility variables, a significantly larger proportion of dementia specific units (34.3\%) were found in highly scored PCC units, compared to the units with low scoring of PCC $(30.6 \%)(p=0.019)$. Units with higher scores of PCC had significantly higher proportion of residents with ADL dependency (50.9\%) compared to units with lower scoring of PCC (49.1\%) (see Table 4). It was also found that the number of beds per units were significantly lower 12.4 (SD 5.8) in units with high PCC scoring compared to in units with low scoring of PCC 13.4 (SD 5.8). No significant differences were found related to ownership in terms of public or privately-operated nursing homes (see Table 4).

\section{Discussion}

This study aimed to explore factors characterizing high and low PCC nursing home units, with focus on leadership, staff, resident and facility variables. This study showed that leadership engagement and support were scored higher in highly person-centred units, which is in line with previous Swedish nursing home studies [24, 25]. More specifically, the findings showed that high PCC-units were characterised by having leaders engaging in staff knowledge, professional development and leaders supporting staff to provide care based on the individual older person's needs. Furthermore, working to improve the team spirit as a leader, as well as being aware of the quality provided by staff were scored higher in high PCC units. Other studies have described that developing PCC requires leaders that acknowledge staffs' unique competences and skills, are engaged in care

Table 3 Comparison of leadership engagement in units with high versus low degree of PCC

\begin{tabular}{|c|c|c|c|c|c|}
\hline & \multicolumn{2}{|c|}{$\begin{array}{l}\text { Low degree } \\
\text { of PCC }\end{array}$} & \multicolumn{2}{|c|}{$\begin{array}{l}\text { High degree } \\
\text { of PCC }\end{array}$} & \multirow[t]{2}{*}{$\begin{array}{l}p \text { - } \\
\text { value }\end{array}$} \\
\hline & $\mathrm{n}^{1}$ & $\mathrm{~m}(\mathrm{SD})$ & $\mathrm{n}^{1}$ & $\mathrm{~m}(\mathrm{SD})$ & \\
\hline To what extent is your manager engaged in issues related to your knowledge / skills at work? & 1817 & $\begin{array}{l}3.3 \\
(1.04)\end{array}$ & 1659 & $\begin{array}{l}3.9 \\
(0.95)\end{array}$ & 0.000 \\
\hline To what extent is your manager engaged in issues related to your professional development at work? & 1820 & $\begin{array}{l}3.3 \\
(1.05)\end{array}$ & 1663 & $\begin{array}{l}3.9 \\
(0.97)\end{array}$ & 0.000 \\
\hline To what extent is your manager aware of the quality of the work you do? & 1812 & $\begin{array}{l}3.2 \\
(1.11)\end{array}$ & 1661 & $\begin{array}{l}3.8 \\
(1.01)\end{array}$ & 0.000 \\
\hline $\begin{array}{l}\text { To what extent does your manager support you in providing care that is based on the individual older } \\
\text { person's needs? }\end{array}$ & 1816 & $\begin{array}{l}3.4 \\
(1.06)\end{array}$ & 1656 & $\begin{array}{l}4.1 \\
(0.96)\end{array}$ & 0.000 \\
\hline To what extent does your manager consciously work to improve the team spirit/mood of the staff group? & 1815 & $\begin{array}{l}3.1 \\
(1.16)\end{array}$ & 1658 & $\begin{array}{l}3.8 \\
(1.07)\end{array}$ & 0.000 \\
\hline To what extent do you get supervision of a reg. Nurse in the direct care provision? & 1820 & $\begin{array}{l}3.3 \\
(1.13)\end{array}$ & 1661 & $\begin{array}{l}3.8 \\
(1.05)\end{array}$ & 0.000 \\
\hline
\end{tabular}

${ }^{1} \mathrm{n}=$ staff assessments. Does not always add up to 3605 staff all variables due to missing items 
Table 4 Comparison of staff, resident and facility characteristics' between units with high and low degree of PCC

\begin{tabular}{|c|c|c|c|c|c|}
\hline & \multicolumn{2}{|c|}{ Low degree of PCC } & \multicolumn{2}{|c|}{ High degree of PCC } & \multirow{2}{*}{$\begin{array}{l}p \text { - } \\
\text { value }\end{array}$} \\
\hline & $\mathrm{n}^{1}(\%)$ & m (SD) & $\mathrm{n}^{1}(\%)$ & m (SD) & \\
\hline \multicolumn{6}{|l|}{ Staff } \\
\hline Age (Years) & & $47(11.2)$ & & $46.2(11.4)$ & 0.051 \\
\hline \multicolumn{6}{|l|}{ Sex } \\
\hline Women & $1748(95.6)$ & & $1600(95.2)$ & & \\
\hline Men & $81(4.4)$ & & $81(4.8)$ & & 0.582 \\
\hline Years of experience in aged care & & $18.3(10.3)$ & & $17.6(10.4)$ & 0.074 \\
\hline Years in this nursing home unit & & $10.2(8.2)$ & & $9.6(7.8)$ & 0.029 \\
\hline \multicolumn{6}{|l|}{ Education } \\
\hline Nurse & $5(0.3)$ & & $7(0.4)$ & & 0.327 \\
\hline Enrolled nurse & $1468(80.7)$ & & $1404(84.6)$ & & 0.002 \\
\hline Nurse assistants & $258(14.2)$ & & $196(11.8)$ & & 0.021 \\
\hline No formal education & $47(2.6)$ & & $33(2.0)$ & & 0.144 \\
\hline Other & $40(2.2)$ & & $60(1.7)$ & & 0.016 \\
\hline \multicolumn{6}{|l|}{ Resident } \\
\hline Age & & $85.4(7.9)$ & & $85.6(7.8)$ & 0.454 \\
\hline \multicolumn{6}{|l|}{ Sex } \\
\hline Women & $1428(67.8)$ & & $1576(67.4)$ & & \\
\hline Men & $678(32.2)$ & & $764(32.6)$ & & 0.746 \\
\hline Length of stay (months) & & $31.1(31.3)$ & & $30.2(35.1)$ & 0.460 \\
\hline Cognitive impairment & $1281(68.7)$ & & $1316(63.1)$ & & 0.000 \\
\hline ADL dependent & $1154(49.1)$ & & $1195(50.9)$ & & 0.008 \\
\hline \multicolumn{6}{|l|}{ Facility } \\
\hline Number of beds per unit & & $13.4(5.8)$ & & $12.4(5.8)$ & $>0.001$ \\
\hline Public nursing home ${ }^{2}$ assessmetns & $1566(94.6)$ & & 1439 (93.4) & & \\
\hline Private nursing home ${ }^{2}$ & $90(5.4)$ & & $102(6.6)$ & & 0.159 \\
\hline Dementia specific unit ${ }^{2}$ & $559(30.6)$ & & $571(34.3)$ & & \\
\hline General unit ${ }^{2}$ & $1269(69.4)$ & & $1094(65.7)$ & & 0.019 \\
\hline
\end{tabular}

${ }^{1} \mathrm{n}$ does not always add up to 3605 staff or 4831 residents in all variables due to missing item

${ }^{2} \mathrm{n}=\mathrm{PCC}$ assessments by staff

practices as well as promotes team performance [5760]. It has been shown that when staff feel supported, acknowledged and valued at work, optimal performance and commitment are likely to follow [57-60]. One interpretation of this study's findings is, when staffs' individual knowledge, competence and the quality of their work is acknowledged and supported by their leader, a person-centred approach can be nurtured, both among the individual staff member and within the team.

The results also show that staff in high PCC units scored that they received supervision of a registered nurse $(\mathrm{RN})$ in the direct care provision to a larger extent that in units with low PCC. Escrig-Pinol, Corazzini, Blodgett, Chu, \& McGilton [61], reports that effective nurse supervisors and support may improve work environments and staff's ability to respond to residents' needs in a timely, effective and compassionate manner.
The expertise and clinical excellence a RN holds has shown to be crucial to build a person-centred approach [62]. Based on this, providing supervision to direct care staff appear to be an important focus of efforts when seeking to improve PCC.

The results also indicate that high PCC-units are characterised by a significantly higher proportion of staff with higher educational qualification. This has been elaborated in person-centred theory [2]. They postulate that a prerequisite is that staff have competence, being committed to the job, being able to demonstrate clarity of beliefs and values, and also knowledge and skills to make decisions' and prioritise care [2]. In Sweden, the education of enrolled nurses is twice as long as nurse's assistants' education, hence it seems reasonable that a longer education may have contributed to a foundation of the principles 
necessary for PCC. However, this finding is contrary to a previous Canadian study [29], where level of education did not influence the provision of PCC and it was reported that individual factors such as education exerted very little influence on staffs' ability to provide PCC, whereas access to resources and seemed to be more of a predictor. This study adds new insights on structural conditions of significance for PCC, as de facto the proportion of staff with enrolled nursing education was significantly higher in high PCC units. This finding contributes to the literature as staff competence has been highlighted as a critical element in person-centred theory [2, 19]. Staff work experience was significantly shorter in high PCC units compared to units with low degree of PCC. It is well known that cultural values of conservative traditions can maintain a strong influence over long periods of time, with resistance to change traditional care to a more person-oriented care as a consequence [63-65]. One can interpret that staff with shorter work experience more easily adapt to this person-centred culture shift, preferred by the national guidelines in Sweden [41] than staff with long experience of working with traditional care models. If this is the case here, subsequent studies need to be explored.

A larger proportion of dementia specific units were found in high PCC units, compared to units with low PCC. It was also found that the number of beds per units were lower in units with high PCC compared to in units with low PCC. This is consistent with previous findings from Swedish nursing home [25], where small, dementia-adapted environments characterised high PCC units in nursing homes. Previous research has reported that dementia-adapted environments may contribute to maintaining autonomy and independence and support social interactions and sense of self [66]. A reasonable implication is the need to tailor the physical environment to meet the individual needs of the residents and create small, homelike environments that allow the residents to be an active participant in everyday life rather than a passive recipient of care [66]. Swedish nursing home care has undergone a transformation under the last decade with a rapidly growing share of private actors, from $1 \%$ in 1990 to $16 \%$ in 2010 [67], to approximately $21 \%$ in 2016 [30]. The proponents argued that contracting nursing homes would lead the private actors to develop better ways to provide care with a quality improvement as a result $[68,69]$. However, this study's finding did not show any care quality differences in terms of PCC provision, related to the ownership of the nursing homes.

Previous intervention research from health care contexts [70], showed that a leadership emphasised PCC values and working practice, and interprofessional team working was facilitators' for implementing personcentred care in hospital contexts. This can be situated as this study findings as highly person-centred units were characterised by leader engaging and support staff in providing a care that is based on the individual older person's needs and works to improve the team spirit. This implies that this current study's finding can be used as managerial strategies when designing and developing person-centred interventions in nursing homes care contexts as well. In summary, this study contributes to the existing research evidence, by suggesting that the support from managers and leaders is important for facilitating PCC, and highlights the importance of manager and leader support in daily care to enact staff to provide such care. However, further comparative, longitudinal and interventional studies would be valuable to confirm or reject these findings on leading towards PCC.

\section{Methodological considerations}

This cross-sectional study cannot answer questions of causal nature. All resident data is proxy-rated which may introduce rate bias when rating items concerning one's own work. This has been addressed with written information to the raters. Proxy-rated resident data may introduce recall and/or observer bias; still, it may be the best source of information due to the high prevalence of cognitive impairment in the sample, and the time the proxies had known the person they assessed was fairly long, indicating good knowledge about the older person. As this study draws on extensive cross-sectional randomised data from a national sample of staff and residents in Swedish nursing homes, this may serve as a means of avoiding systematic bias. The results are from a Swedish context, and thus, may affect the findings generalizability. However, as this study draws on extensive cross-sectional randomised data from a national sample of staff in Swedish nursing homes, it seems reasonable to argue that the findings could be applied across different contexts and settings with similar care structure. Differences between nursing homes were not explored, as this was not the aim of this study, still an important research area subsequent studies can explore.

\section{Conclusions and recommendations}

This study provides information about leadership, staff, resident, facility determinants with capacity to enhancing person-centred care provision, were support from leaders seems important when striving towards personcentred care in daily practice. The study also highlights several environmental factors associated with highly person-centred units. The findings suggest that factors of leadership, staff, resident and facility can be identified 
and targeted in efforts to facilitate PCC practice in nursing home care. Addressing these gaps may provide important insight into the factors that help or hinder the provision and development PCC. The study findings can be interpreted as predictors or facilitators for PCC and be used for leadership training and/or development initiatives, or even as an empirical knowledge base for nursing curricula on nursing leadership and development. If nursing homes units or facilities struggles with implementing person-centred care, it seems that managers have an important role to promote the movement towards a person-centred practice of care, by supporting their staff in daily care, and engaging in staff knowledge and professional development. It also seems important to target and adjust environmental factors, such as provide small and dementia adapted environments to match the residents' personal preferences and capacity. It also seems reasonable to suggest that educational initiatives need to be contextually embedded and tailored to meet the person in need of care when seeking to develop and improve person-centred nursing home units. This study provides guidance for practitioners when designing, developing and adapting person-centred units in aged care contexts.

\section{Abbreviations}

PCC: Person-centred care; WHO: World Health Organization; ADL: Activities in daily living; RN: Registered nurse

\section{Acknowledgements}

The authors wish to thank all participating staff and their managers for taking part in this study by completing the questionnaires.

\section{Authors' contributions}

$A B$ and $A S$ : study design, analysis of data, literature review and drafting of manuscript. PO: study supervision and drafting of manuscript. All authors were involved in manuscript preparation, and read and approved the final manuscript.

\section{Funding}

The study was financed by the Swedish Research Council for Health, Working life and Welfare (2014-4016) and the Swedish Research Council (521-2014-2715). The funding bodies had no role in the design of the study, the data collection, data analysis or interpretation of data. Nor did they have any influence on the writing on the manuscript or decision to submit the paper. Open Access funding provided by Umea University.

\section{Availability of data and materials}

The datasets used and/or analyzed during the current study are available from the corresponding author on reasonable request.

\section{Declarations}

\section{Ethics approval and consent to participate}

This study has received ethical approval from the Regional Ethical Review Board in Umeå, Sweden (Dnr 2013-269-31). The questionnaires were completed by nursing home staff without the direct involvement of the residents. Informed consent, written or verbal, was not obtained from all residents but an opt-out consent procedure approved by the ethics committee, was used. Written information about the study was provided to all participating staff as well as on information posters in the entrances to the nursing homes, and residents as well as their relatives could decline participation if they did not want to contribute their data. In agreement with the Swedish Ethical Review Board, a returned and completed survey was considered as a consent to participate. The ethical approval was obtained from the Regional Ethical Review Board in Umeå, Sweden (Dnr 2013-269-31).

\section{Competing interests}

The authors declare that they have no competing interests.

\section{Author details}

'Department of Nursing, Umeå University, SE-901 87 Umeå, Sweden. ${ }^{2}$ NVS, Division of Nursing, Karolinska Institutet, Huddinge, Sweden. ${ }^{3} \mathrm{NVS}$, Division of Neurogeriatrics, Department of Nursing, Karolinska Institutet, Huddinge, Sweden.

Received: 20 August 2020 Accepted: 24 August 2021

Published online: 16 September 2021

\section{References}

1. Edvardsson D, Winblad B, Sandman PO. Person-centred care of people with severe Alzheimer's disease: current status and ways forward. Lancet Neurol. 2008;7(4):362-7.

2. McCormack B, McCance TV. Development of a framework for personcentred nursing. J Adv Nurs. 2006;56(5):472-9.

3. Brooker DL, I. Person-centred dementia care - making services better with the VIPS framework. London and Philadelphia: Jessica Kingsley Publishers; 2015.

4. Sjogren K, Lindkvist M, Sandman PO, Zingmark K, Edvardsson D. Personcentredness and its association with resident well-being in dementia care units. J Adv Nurs. 2013;69(10):2196-205.

5. Terada S, Oshima E, Yokota O, Ikeda C, Nagao S, Takeda N, et al. Personcentered care and quality of life of patients with dementia in long-term care facilities. Psychiatry Res. 2013;205(1-2):103-8.

6. Bone C, Cheung G, Wade B. Evaluating person centred care and dementia care mapping in a psychogeriatric hospital in New Zealand: a pilot study. NZJOT. 2010;57(1):35-40.

7. Rokstad AM, Rosvik J, Kirkevold O, Selbaek G, Saltyte Benth J, Engedal K. The effect of person-centred dementia care to prevent agitation and other neuropsychiatric symptoms and enhance quality of life in nursing home patients: a 10-month randomized controlled trial. Dement Geriatr Cogn Disord. 2013;36(5-6):340-53.

8. Chenoweth L, King MT, Jeon YH, Brodaty H, Stein-Parbury J, Norman R, et al. Caring for Aged Dementia Care Resident Study (CADRES) of person-centred care, dementia-care mapping, and usual care in dementia: a clusterrandomised trial. Lancet Neurol. 2009;8(4):317-25.

9. Fossey J, Ballard C, Juszczak E, James I, Alder N, Jacoby R, et al. Effect of enhanced psychosocial care on antipsychotic use in nursing home residents with severe dementia: cluster randomised trial. BMJ. 2006; 332(7544):756-61.

10. Brooker DJ, Woolley RJ. Enriching opportunities for people living with dementia: the development of a blueprint for a sustainable activity-based model. Aging Ment Health. 2007;11(4):371-83.

11. Wallin AO, Jakobsson U, Edberg AK. Job satisfaction and associated variables among nurse assistants working in residential care. Int Psychogeriatr. 2012; 24(12):1904-18.

12. Edvardsson D, Fetherstonhaugh D, McAuliffe L, Nay R, Chenco C. Job satisfaction amongst aged care staff: exploring the influence of personcentered care provision. Int Psychogeriatr. 2011;23(8):1205-12.

13. Sjogren K, Lindkvist M, Sandman PO, Zingmark K, Edvardsson D. To what extent is the work environment of staff related to person-centred care? A cross-sectional study of residential aged care. J Clin Nurs. 2015;24(9-10):1310-9.

14. Moyle W, Murfield JE, Griffiths SG, Venturato L. Care staff attitudes and experiences of working with older people with dementia. Australas J Ageing. 2011;30(4):186-90.

15. Edvardsson D, Sandman PO, Nay R, Karlsson S. Predictors of job strain in residential dementia care nursing staff. J Nurs Manag. 2009;17(1):59-65.

16. WHO. Global strategy on people-centred and integrated health services: an overview of evidence. 2015.

17. McCance TM, Dewing BJ. An exploration of person-centredness in practice. Faculty of Science, Medicine and Health - Papers: part A 2470; 2011.

18. Epp T. Person-centred dementia care: a vision to be refined. Can Alzheimer Dis Rev. 2003;5(3):14-9.

19. McCormack BM, T. Perso-centred nursing theory and practice. Chichester: Wiley-Blackwell Publishing; 2010. 
20. Rokstad AM, Vatne S, Engedal K, Selbæk G. The role of leadership in the implementation of person-centred care using dementia care mapping: a study in three nursing homes. J Nurs Manag. 2015;23(1):15-26.

21. Rosemond CA, Hanson LC, Ennett ST, Schenck AP, Weiner BJ. Implementing person-centered care in nursing homes. Health Care Manag Rev. 2012;37(3): 257-66.

22. Stein-Parbury J, Chenoweth L, Jeon YH, Brodaty H, Haas M, Norman R. Implementing person-centered care in residential dementia care. Clin Gerontol. 2012;35(5):404-24.

23. Chenoweth L, Forbes I, Fleming R, King MT, Stein-Parbury J, Luscombe G, et al. PerCEN: a cluster randomized controlled trial of person-centered residential care and environment for people with dementia. Int Psychogeriatr. 2014;26(7):1147-60.

24. Backman A, Sjögren K, Lindkvist M, Lövheim H, Edvardsson D. Towards person-centredness in aged care - exploring the impact of leadership. $J$ Nurs Manag. 2016;24(6):766-74

25. Sjögren K, Lindkvist M, Sandman P-O, Zingmark K, Edvardsson D. Organisational and environmental characteristics of residential aged care units providing highly person-centred care: a cross sectional study. BMC Nurs. 2017;16(1):44

26. Miller SC, Miller EA, Jung H-Y, Sterns S, Clark M, Mor V. Nursing home organizational change: the "culture change" movement as viewed by longterm care specialists. Med Care Res Rev. 2010;67(4_suppl):65S-81S.

27. Jeon Y-H, Simpson JM, Li Z, Cunich MM, Thomas TH, Chenoweth L, et al. Cluster randomized controlled trial of an aged care specific leadership and management program to improve work environment, staff turnover, and care quality. J Am Med Dir Assoc. 2015;16(7):629.e19-.e28.

28. Sandström B, Borglin G, Nilsson R, Willman A. Promoting the implementation of evidence-based practice: a literature review focusing on the role of nursing leadership. Worldviews Evid-Based Nurs. 2011;8(4):212-23.

29. Caspar S, Cooke HA, O'Rourke N, MacDonald SWS. Influence of individual and contextual characteristics on the provision of individualized care in long-term care facilities. The Gerontologist. 2013;53(5):790-800.

30. Winblad U, Blomqvist P, Karlsson A. Do public nursing home care providers deliver higher quality than private providers? Evidence from Sweden. BMC Health Serv Res. 2017;17(1):487.

31. Edvardsson D, Backman A, Bergland $\AA$, Björk S, Bölenius K, Kirkevold M, Winblad B. The Umeå ageing and health research programme (U-Age): Exploring person-centred care and health-promoting living conditions for an ageing population. Nordic J Nurs Res. 2016;36(3):168-74.

32. (NBHW) NBoHaW. Nationell ledarskapsutbildning för chefer inom äldreomsorg (in Swedish). 2011.

33. Backman A, Sjögren K, Lindkvist M, Lövheim H, Edvardsson D. Characteristics of highly rated leadership in nursing homes using item response theory. J Adv Nurs. 2017;73(12):2903-13.

34. National Board of Health and Welfare. Socialstyrelsen. Vård- och omsorgsutbildade- idag och i framtiden (in Swedish). 2015.

35. Törnquist A. What to do and how to be : a study of the professional skills among unit managers and nursing staff within the institutions of eldercare [Doctoral thesis, monograph]. Stockholm: HLS Förlag; 2004

36. European qualifications framework. Initial vocational education and training: focus on qualifications at levels 3 and 4. Luxembourg: Publications Office of the European Union. Cedefop research paper; No 77. 2020. http://data. europa.eu/doi/10.2801/114528.

37. National Board of Health and Welfare. Socialstyrelsen. Öppna jämförelser 2018-Vård och omsorg om äldre. Jämförelser mellan kommuner och län (in Swedish). 2018.

38. SOFS. Socialstyrelsens allmänna råd om grundläggande kunskaper hos personal som arbetar i socialtjänstens omsorg om äldre (In Swedish). In: National Board of Health and Welfare, editor; 2011.

39. Eurodiaconia. The education, training and qualifications of nursing and care assistants across Europe. 2016.

40. Education SCfH. Referensramar för svenska kvalifikationer och examina (In swedish). 2021. Available from: https://www.uhr.se/bedomning-av-utlandskutbildning/enic-naric-sverige/referensramar-for-svenska-kvalifikationer/?ram= 2\&level=5.

41. National Board of Health and Welfare. Socialstyrelsen. Nationella riktlinjer för vård och omsorg vid demenssjukdom- Stöd för styrning och ledning-remissversion (in Swedish). 2017. http://www.socialstyrelsen.se/publikationer2017/2017-12-2.

42. Bjork S, Juthberg C, Lindkvist M, Wimo A, Sandman PO, Winblad B, et al. Exploring the prevalence and variance of cognitive impairment, pain, neuropsychiatric symptoms and ADL dependency among persons living in nursing homes; a cross-sectional study. BMC Geriatr. 2016;16:154.

43. NBoHaWN. The National Board of Health and Welfares statistics database. 2020. https://sdb.socialstyrelsen.se/if_ald/resultat.aspx2020.

44. Lagergren M. The systems of care for frail elderly persons: the case of Sweden. Aging Clin Exp Res. 2002;14(4):252-7.

45. Hällsten FTS. Personalansvar och medarbetarskap-om relationen mellan organisation och medarbetare. Gothenburg: Gothenburg University; 2002.

46. Beck I. Att fokusera på "varandet" i en värld av görande. Stöd till personalen i ett palliativt förhållningssätt vid vård-och omsorgsboende för äldre. Lund: Lund University; 2013.

47. Katz S, Ford AB, Moskowitz RW, Jackson BA, Jaffe MW. Studies of illness in the aged. The index of ADL: a standardized measure of biological and psychosocial function. JAMA. 1963;185:914-9.

48. Hulter Åsberg K. ADL-trappan. Studentlitteratur. Katz, S. et al. (1963). Studies of illness in the aged. The index of ADL: a standardized measure of biological and psychosocial function. JAMA. 1990;185(12):914-9.

49. Skoldunger A, Wimo A, Sjogren K, Bjork S, Backman A, Sandman PO, et al. Resource use and its association to cognitive impairment, ADL functions, and behavior in residents of Swedish nursing homes: results from the $U$ Age program (SWENIS study). Int J Geriatr Psychiatry. 2019;34(1):130-6.

50. Adolfsson R, Gottfries CG, Nystrom L, Winblad B. Prevalence of dementia disorders in institutionalized Swedish old people. The work load imposed by caring for these patients. Acta Psychiatr Scand. 1981;63(3):225-44.

51. Lövheim H. Psychotropic and analgesic drug use among old people: with special focus on people living in institutional geriatric care. Umeå: Umeå University; 2008.

52. Edvardsson D, Fetherstonhaugh D, Nay R, Gibson S. Development and initial testing of the Person-Centered Care Assessment Tool (P-CAT). Int Psychogeriatr. 2010;22(1):101-8.

53. Sjogren $K$, Lindkvist $M$, Sandman PO, Zingmark K, Edvardsson D Psychometric evaluation of the Swedish version of the Person-Centered Care Assessment Tool (P-CAT). Int Psychogeriatr. 2012;24(3):406-15.

54. Shrive FM, Stuart H, Quan H, Ghali WA. Dealing with missing data in a multi-question depression scale: a comparison of imputation methods. BMC Med Res Methodol. 2006:6(1):57.

55. Björk S. Exploring resident thriving in Swedish nursing homes : the Umeå ageing and health research programme (U-Age) thesis I [Doctoral thesis, comprehensive summary]. Umeå: Umeå universitet; 2017.

56. Backman A. Leadership: person-centred care and the work situation of staff in Swedish nursing homes [Doctoral thesis, comprehensive summary]. Umeå: Umeå universitet; 2018.

57. McGilton KS, Sidani S, Boscart VM, Guruge S, Brown M. The relationship between care providers' relational behaviors and residents mood and behavior in long-term care settings. Aging Ment Health. 2012;16(4):507-15.

58. Backman A, Ahnlund P, Sjögren K, Lövheim H, McGilton KS, Edvardsson D. Embodying person-centred being and doing: leading towards person-centred care in nursing homes as narrated by managers. J Clin Nurs. 2020;29(1-2):172-83.

59. Lynch BM, McCance T, McCormack B, Brown D. The development of the person-centred situational leadership framework: revealing the being of person-centredness in nursing homes. J Clin Nurs. 2018:27(1-2):427-40.

60. Cardiff S, McCormack B, McCance T. Person-centred leadership: a relational approach to leadership derived through action research. J Clin Nurs. 2018; 27(15-16):3056-69.

61. Escrig-Pinol A, Corazzini KN, Blodgett MB, Chu CH, McGilton KS. Supervisory relationships in long-term care facilities: a comparative case study of two facilities using complexity science. J Nurs Manag. 2019;27(2):311-9.

62. McGilton KS, Heath $\mathrm{H}$, Chu CH, Boström A-M, Mueller C, Boscart MV, et al. Moving the agenda forward: a person-centred framework in long-term care. Int J Older People Nursing. 2012;7(4):303-9.

63. Koren M. Person-centered care for nursing home residents: the culturechange movement. Health Aff. 2010;29(2):312-7.

64. Carlström Eric D, Ekman I. Organisational culture and change: implementing person-centred care. J Health Organ Manag. 2012;26(2):175-91.

65. McGreevy J. Implementing culture change in long-term dementia care settings. Nurs Stand. 2016;30(19):44-50.

66. Davis S, Byers S, Nay R, Koch S. Guiding design of dementia friendly environments in residential care settings: considering the living experiences. Dementia. 2009;8(2):185-203.

67. Blomqvist. P WU. Privata aktörer och kontraktsstyrning i äldreomsorgen: förbättras kvaliteten? 2011. 
68. 1992/93:43 P. Ökad konkurrens i kommunal verksamhet (in Swedish). 1992

69. Civildepartementet S. SOU 1991:104. Konkurrensen inom den kommunala sektorn, Civildepartementet, editor. Stockholm; 1991.

70. Moore L, Britten N, Lydahl D, Naldemirci Ö, Elam M, Wolf A. Barriers and facilitators to the implementation of person-centred care in different healthcare contexts. Scand J Caring Sci. 2017;31(4):662-73.

\section{Publisher's Note}

Springer Nature remains neutral with regard to jurisdictional claims in published maps and institutional affiliations.

Ready to submit your research? Choose BMC and benefit from:

- fast, convenient online submission

- thorough peer review by experienced researchers in your field

- rapid publication on acceptance

- support for research data, including large and complex data types

- gold Open Access which fosters wider collaboration and increased citations

- maximum visibility for your research: over $100 \mathrm{M}$ website views per year

At $B M C$, research is always in progress.

Learn more biomedcentral.com/submissions 